\title{
NECESSIDADE DE CUIDADO E DESEJO DE PARTICIPAÇÃO NO PARTO DE GESTANTES RESIDENTES EM LONDRINA-PARANÁ ${ }^{1}$
}

\author{
Thelma Malagutti Sodré2, Isabel Cristina Bonadio ${ }^{3}$, Maria Cristina Pinto de Jesus ${ }^{4}$, Miriam Aparecida Barbosa \\ Merighi $^{5}$
}

${ }^{1}$ Artigo extraído da tese - Necessidade de cuidado e de participação no parto: a voz de um grupo de gestantes de LondrinaParaná, Programa de Pós-graduação em Enfermagem, Escola de Enfermagem da Universidade de São Paulo (USP), 2010.

${ }^{2}$ Mestre em Fundamentos de Enfermagem. Professora Assistente do Departamento de Enfermagem da Universidade Estadual de Londrina. Paraná, Brasil. E-mail: thelminha@sercomtel.com.br

${ }^{3}$ Doutora em Enfermagem. Professora Doutora do Departamento de Enfermagem Materno-Infantil e Psiquiátrica da Escola de Enfermagem da USP. São Paulo, Brasil. E-mail: ibonadio@usp.br

${ }^{4}$ Doutora em Enfermagem. Professora Associado do Departamento de Enfermagem Básica da Faculdade de Enfermagem da Universidade Federal de Juiz de Fora. Minas Gerais, Brasil. E-mail: cristina.pinto@acessa.com

${ }^{5}$ Doutora em Enfermagem. Professora Titular do Departamento de Enfermagem Materno-Infantil e Psiquiátrica da Escola de Enfermagem da USP. São Paulo, Brasil. E-mail: merighi@usp.br

RESUMO: A participação da mulher na tomada de decisão, nas ações de promoção à saúde, é um direito que deve ser respeitado. Este estudo buscou compreender a necessidade de cuidado e o desejo de participação nas decisões sobre o parto de gestantes de Londrina-PR. Utilizou-se a pesquisa fundamentada na fenomenologia social. As gestantes foram entrevistadas no período de agosto a novembro de 2008. Foram analisados 14 depoimentos, resultando na formação de quatro categorias: preferência pelo tipo de parto, insegurança, necessidade de cuidado e tomada de decisão no parto. Os resultados evidenciaram que, apesar de desejarem participar do seu parto e de verbalizarem suas necessidades, escolhas e preferências, as mulheres não encontram condições favoráveis para que suas necessidades de cuidado e o desejo de participação nas decisões sobre o parto sejam viabilizados; fato que interfere nas relações face a face e impede o direito à escolha informada em relação ao parto.

DESCRITORES: Enfermagem obstétrica. Pré-natal. Parto humanizado. Tomada de decisões. Pesquisa qualitativa.

\section{PREGNANT WOMEN CARE NEEDS AND DESIRES TO PARTICIPATE IN THEIR DELIVERY DECISIONS: A STUDY CARRIED OUT IN LONDRINA, PARANÁ, BRAZIL}

\begin{abstract}
Women's participation in decision making involving health care promotion is a right that should be respected. This study aimed to better understand the need for care and the desire to participate in delivery decisions among pregnant women in Londrina, PR, Brazil. This study was based on social phenomenology. The pregnant women were interviewed from August to November, 2008. Statements from 14 pregnant women were analyzed and were divided into four categories: type of delivery preference; insecurity; the need for care; and decision-making in delivery. Results showed that although women expressed their needs and their wish to participate in the decisions regarding their delivery, they did not find favorable conditions so that their care needs and desire to participate in delivery decisions were made possible, a fact which interferes in face-to-face relationships and impedes the right to informed choices with respect to the delivery process.
\end{abstract}

DESCRIPTORS: Obstetrics nursing. Prenatal. Humanized delivery. Decision making. Qualitative research.

\section{LA NECESIDAD DE ATENCIÓN Y EL DESEO DE PARTICIPAR EN EL PARTO DE LAS MUJERES EMBARAZADAS RESIDENTES EN LONDRINA- PARANÁ, BRAZIL}

RESUMEN: La participación de la mujer en la toma de decisiones y en las acciones para promover la salud, es un derecho que debe ser respetado. Este estudio trata de comprender la necesidad de cuidado y el deseo de participar en las decisiones sobre el parto de las mujeres embarazadas residentes en Londrina-PR. Es una investigación basada en la fenomenología social. Las embarazadas fueron entrevistadas en el período de agosto a noviembre de 2008. Se analizaron 14 declaraciones, lo que resultó en la formación de cuatro categorías: preferencia por el tipo de parto, inseguridad, necesidad de atención y toma de decisiones en el parto. Los resultados mostraron que a pesar de desear participar de su parto y de verbalizar sus necesidades, opciones y preferencias, las mujeres no encontraron condiciones favorables para que sus necesidades de atención y el deseo de participar en las decisiones sobre el parto sean viabilizadas; hecho que interfiere en las relaciones cara a cara e impide el derecho a la elección informada en relación al parto.

DESCRIPTORES: Enfermería obstétrica. Prenatal. Parto humanizado. Tomada de decisiones. Pesquisa cualitativa. 


\section{INTRODUÇÃO}

A informação e a decisão informada, nas ações de saúde, são direitos da mulher que devem ser promovidos. No processo da parturição, a mulher tem a expectativa de receber informações sobre o que acontece com ela e com o seu bebê e sobre o modo de participação, pois deseja adaptarse ao modelo hospitalar vigente. $O$ profissional de saúde tem a obrigação ética e legal de oferecer informações claras e completas sobre o cuidado, os tratamentos e as alternativas, e dar à mulher a oportunidade de participar das decisões em relação ao que lhe foi informado. ${ }^{1-2}$ Neste contexto, deve-se considerar a quantidade e o tipo de informação que o consumidor quer ou necessita para sentir-se informado; por outro lado, é importante lembrar que a tomada de decisão depende, também, de experiências prévias, de valores, de crenças, de medos e de informações obtidas de outras fontes. ${ }^{3} \mathrm{~A}$ informação e o empoderamento são mais importantes para a mulher do que a própria participação, em si, na tomada de decisão. ${ }^{4}$

No Brasil, o modelo predominante de assistência ao parto é extremamente intervencionista, pois penaliza a mulher e sua família, ao priorizar as rotinas institucionais em detrimento da fisiologia e dos aspectos sociais e culturais do evento. A distância impressionante entre as evidências científicas e a prática obstétrica é um exemplo do quanto a cultura institucional, técnica, coorporativa, sexual e reprodutiva tem precedência sobre a racionalidade científica, como conhecimento autoritativo, na organização das práticas de saúde. ${ }^{5}$

Em Londrina-PR, é comum o uso excessivo de intervenções e o desrespeito às parturientes, por parte dos profissionais de saúde. A atitude passiva das mulheres, no momento do parto, diante das condutas autoritárias dos profissionais, perpetua-se. A situação pode gerar medo e ansiedade, interferir na fisiologia do parto e até oferecer riscos materno-fetais, pois as relações de vínculos ainda são frágeis.

Essa realidade em relação ao parto e ao nascimento despertou algumas inquietações que acabaram por nortear a presente pesquisa: As mulheres participam do parto? Planejam seu parto? Desejam participar das decisões? O acesso às informações favorece a participação ativa das mulheres? Quais são as suas necessidades durante essa experiência?

As gestantes constituem um grupo social com necessidades e projetos específicos, em rela- ção ao parto, que precisam ser compreendidos. A literatura aponta estudos que se referem às suas expectativas em relação ao tipo de parto, contudo, não há investigações com abordagens compreensivas acerca da necessidade de cuidados e de participação da mulher no parto; fato que motivou esta pesquisa.

Os resultados deste estudo poderão nortear as práticas de assistência ao parto e incrementar o ensino e o conhecimento na área da enfermagem obstétrica.

Assim, este estudo buscou compreender a necessidade de cuidado e o desejo de participação nas decisões sobre o parto de gestantes de Londrina-PR.

\section{REFERENCIAL TEÓRICO-METODOLÓ- GICO}

Trata-se de um estudo fundamentado na fenomenologia social de Alfred Schutz. Ao refletir sobre a necessidade de cuidado e o desejo de participação da mulher no seu parto, buscou-se compreender este fenômeno junto a gestantes, que constituem um grupo social, tomando-se por base a ação individual. Nessa abordagem fenomenológica, a ação social é entendida como uma relação interpessoal, que é estabelecida no mundo vida e que proporciona a vivência intersubjetiva dos significados humanos. ${ }^{6}$

As ações das pessoas são motivadas e esses motivos são existenciais e não meramente psicológicos. No momento da ação, as pessoas baseiam-se em experiências passadas, nas tipificações acerca do mundo e nas situações práticas que lhes são transmitidas por seus familiares, amigos e professores, ou seja, em sua bagagem de conhecimentos disponíveis. Os "motivos-porque" estão relacionados a essas experiências e tipificações. Os "motivos-para" constituem o ponto de vista subjetivo da ação, isto é, a interpretação que a própria pessoa faz da sua ação. As ações individuais originam-se de pensamentos conscientes, que são voluntários e direcionados para o futuro. No contexto da intersubjetividade, as ações individuais se configuram em um sentido social. Nesse sentido, as ações ou comportamentos humanos são direcionados para a realização de uma ação específica - o projeto - que só pode ser interpretado pela própria pessoa, pois somente ela pode definir a sua ação e a maneira como esta se insere na sociedade. ${ }^{7}$

Tendo por base essas concepções de Alfred Schütz, acima descritas, buscou-se compreender o 
fenômeno deste estudo. A perspectiva fenomenológica foi adotada por permitir a compreensão da gestante como pessoa capaz de exteriorizar suas necessidades e de compreender e ser compreendida, no contexto do cuidado do seu parto.

Participaram da pesquisa quatorze gestantes, com idades entre 14 e 37 anos, das quais onze eram primigestas, oito realizavam o pré-natal em serviços públicos de saúde integrados ao Sistema Único de Saúde (SUS) e seis, em serviços privados do Sistema de Saúde Suplementar. Todas as gestantes foram atendidas, no período pré-natal, por médicos. A idade gestacional variou entre 29 e 37 semanas; a opção por este período foi motivada pela proximidade do evento, o que contribuiu para o acesso às informações desejadas sobre a necessidade de cuidado e de participação da mulher na experiência do parto.

O número de participantes foi definido pelos próprios depoimentos, considerados suficientes para alcançar os objetivos e responder às inquietações. Assim, o encerramento da inclusão de novas gestantes foi decidido com base no conjunto dos dados obtidos, que evidenciou a abrangência dos significados contidos nos depoimentos.

A coleta de dados foi realizada de agosto a novembro de 2008 e a aproximação com as gestantes se deu em um Grupo de Gestantes, coordenado e realizado pelo Departamento de Fisioterapia da Universidade Estadual de Londrina, desenvolvido no Ambulatório de Fisioterapia do Hospital Universitário de Londrina, que oferece preparo físico para o período gestacional e para o parto normal. As entrevistas foram realizadas em local, data e horário de preferência das participantes. Assim sendo, doze gestantes foram entrevistadas nas suas residências, e duas em sala de aula próxima ao ambulatório.

Para as gestantes que não tinham experiência anterior de parto, as questões norteadoras foram: Qual a sua expectativa em relação ao seu parto? Como você gostaria de ser cuidada? Você deseja tomar alguma decisão em relação ao seu parto? Qual decisão? Para aquelas com experiência prévia, as questões norteadoras foram: Como foi a sua experiência de parto anterior? Foi como você esperava? Suas necessidades e preferências foram atendidas? Você teve a oportunidade de fazer alguma escolha/ participar de alguma decisão? Quais? Qual a sua expectativa em relação a este próximo parto? Como você gostaria de ser cuidada? Você deseja tomar alguma decisão? Qual decisão?
As entrevistas foram gravadas e, integralmente, transcritas. O sigilo e o anonimato foram respeitados pelo uso das iniciais dos nomes das participantes, seguidos da idade e do número de gestações.

Da análise dos depoimentos emergiram quatro categorias concretas, que expressam aspectos significativos da compreensão e da vivência dos "motivos-para" e dos "motivos-porque" das gestantes: preferência pelo tipo de parto, insegurança, necessidade de cuidado e tomada de decisão. Para a estruturação das categorias, foram seguidos os passos sugeridos por estudiosos da fenomenologia social ${ }^{6}$ : leitura atenta e pormenorizada das narrativas das mulheres, com o objetivo de apreender a vivência motivada das participantes; releitura das transcrições, de modo a identificar as categorias que expressam aspectos significativos da compreensão e da vivência dos "motivos-para" e dos "motivos-porque" das gestantes; agrupamento das unidades de significado que representam convergências de conteúdo dos relatos que compõem as categorias; e análise compreensiva dos agrupamentos de significados com base no referencial teórico-metodológico de Alfred Schütz.

O estudo foi aprovado pelo Comitê de Ética em Pesquisa Envolvendo Seres Humanos da Universidade Estadual de Londrina/Hospital Universitário Regional Norte do Paraná (Parecer CEP n ${ }^{\circ}$ 036/08).

\section{RESULTADOS E DISCUSSÃO}

O contexto de significados - "motivos-porque" - foi revelado por meio dos temas: preferência pelo tipo de parto e insegurança.

As gestantes vivenciaram redes de relacionamento social, por meio das quais as experiências de outras pessoas foram compartilhadas, em uma coexistência, já que as ações são sempre intersubjetivas. Além disso, utilizaram o acervo de conhecimento disponível para determinar as tipificações do senso comum, que se traduziu, para este grupo, na preferência pelo parto normal, evidenciada em mulheres atendidas tanto em serviços públicos como privados: [...] eu estou me preparando pra ter o parto normal, é o que eu sempre quis. Desde quando eu pensava na maternidade, eu já pensava no parto normal (AK, 28 anos, $1^{\text {a }}$ gestação). Algumas gestantes consideraram a possibilidade de uma cesárea, diante de alguma intercorrência no parto: eu prefiro o normal, não quero uma cesárea, só se for de última hora, [...] porque o parto cesárea, ele é 
mais sofredor pra mulher (A, 19 anos, $1^{\mathrm{a}}$ gestação). A preferência das multigestas também foi pelo parto normal, e a opção pela cesárea ocorreu em situações de risco materno e fetal: [...] neste eu gostaria que fosse uma cesariana [...] eu acho que devia marcar uma cesárea [...] por causa do neném (Comunicação interventricular diagnosticada por ultrassonografia) (I, 31 anos, $5^{a}$ gestação).

No que diz respeito ao parto normal, as alternativas apresentadas pelas gestantes incluíram o natural, de cócoras, na água, humanizado, domiciliar e sem dor. É possível que o conhecimento sobre as diversas alternativas de parto normal apresentadas tenha sido adquirido não somente com as experiências de familiares e amigas, uma vez que as maternidades de Londrina não oferecem todas essas opções, mas, também, por meio da mídia e da Internet, que parece terem sido importantes instrumentos para a apreensão de conceitos sobre o tema: [...] comecei a procurar e pesquisar nos sites sobre o assunto, [...] e eu descobri que não era, que eu tinha que investigar, que pesquisar [...] (K, 30 anos, $1^{\mathrm{a}}$ gestação).

Ao buscar informações sobre o atendimento nas instituições hospitalares em Londrina, uma gestante mostrou seu descontentamento por não poder escolher o parto com analgesia, fato percebido por ela como desrespeito aos direitos da mulher sobre o seu corpo, assim como, de optar sobre o tipo de parto, o que descaracteriza o atendimento humanizado que a instituição alega oferecer: [...] pra mim humanizado quer dizer a forma que a pessoa se sinta bem e não é o que ocorre, [...] eu falei, tá, e daí, no caso se a mãe escolher um parto com analgesia, como funciona? Ela falou, não, aqui a mãe não pode escolher. [...] eu falei, não, como assim, não tem opção? É o corpo dela! Ela tem que ser respeitada, é a opção dela! Mas, infelizmente, é assim que acontece! (Z, 26 anos, $1^{\mathrm{a}}$ gestação).

A insegurança emergiu dos mitos, fantasias e medos que apareceram ao se aproximar o momento do parto, influenciados por múltiplos fatores que extrapolaram a própria evolução fisiológica da gestação. As gestantes convivem com a ambiguidade da alegria de conhecer o filho e do medo de parir, gerada pelas experiências de vida pessoal, pelas histórias de parto ouvidas ou vivenciadas junto a um familiar ou amiga mais próxima, pelas informações dos profissionais de saúde e por tantas outras, acessadas em todas as fontes disponíveis.

Entre os medos revelados estavam o medo do afastamento rápido e desnecessário do recémnascido; de ficar sozinha; da dor do parto; das condições de vitalidade do recém-nascido; dos imprevistos do parto; da qualidade da assistência, caracterizada pela falta de atenção e desrespeito dos profissionais: [...] eu fiquei sozinha o tempo todo no quarto! E aquela sensação foi muito terrível! [...] eu não queria sentir de novo [...] (C, 32 anos, $4^{\mathrm{a}}$ gestação); ah, eu queria que tivesse o parto sem dor, só que não tem lá. Ah, eu estou morrendo de medo. [...] que vai doer muito! (Y, 19 anos, $1^{\mathrm{a}}$ gestação; [...] dá um medo, [...] de acontecer alguma coisa com a nenê no hospital [...] (U, 21 anos, $1^{\mathrm{a}}$ gestação); [...] eu chegar lá e eles não deixarem eu de canto, porque falaram assim que eles [...] não ligam (G, 14 anos, $1^{\mathrm{a}}$ gestação).

Os projetos, desejos e expectativas das gestantes, "motivos-para", foram revelados por meio das categorias: necessidade de cuidado e tomada de decisão.

\section{Necessidade de cuidado}

As gestantes apontaram a necessidade de informações e explicações sobre a gestação e sobre os procedimentos que serão realizados durante o parto e sua evolução e atribuíram aos profissionais esta responsabilidade: [...] o médico tem muito que conversar com a gente, dizer tudo que está acontecendo, [...] eu quero um médico assim, que se dedique, [...] que não me trate como só mais uma paciente $(\mathrm{V}, 23$ anos, $1^{\mathrm{a}}$ gestação); [...] ele vai mexer com você, ele tem que explicar todos os detalhes, [...] não exatamente pode ser o médico, por exemplo, as auxiliares também poderiam me explicar e deixar bem claro de tudo, sem dúvida nenhuma. [...] atenção na hora da explicação, pra tranquilizar [...] (D, 19 anos, $1^{\text {a }}$ gestação).

Um estudo mostra que a mulher informada sobre o parto, ainda no período gestacional, apresenta-se mais segura durante a evolução do trabalho de parto e tem maior possibilidade de participar na tomada de decisão, o que influencia, diretamente na sua satisfação em relação ao evento. É perceptível a tranquilidade que ela pode sentir ao vivenciar o trabalho de parto, principalmente, quando ocorre pela primeira vez. ${ }^{8} \mathrm{O}$ profissional de saúde deve valorizar as ações de ouvir, envolver-se, comunicar-se, sintonizar-se com as gestantes; inserir-se no mundo significa comunicar-se com ele e, como comunicação, pressupõe intersubjetividade. São estas as tipificações que sustentam toda relação social, na qual o indivíduo está inserido. ${ }^{9}$

As gestantes ainda destacaram que os profissionais de saúde não devem utilizar linguagem técnica: [...] porque, às vezes, o pessoal usa termo 
técnico [...] isso é meio pecaminoso nas instituições de saúde [...] (Z, 26 anos, $1^{\mathrm{a}}$ gestação). A mulher tem necessidade de explicações claras durante o trabalho de parto, para que sejam minimizadas suas dúvidas e angústias, o que pode aproximar o profissional da mulher e gerar uma relação de confiança e afetividade, que são essenciais para a adequada evolução do parto. Percebe-se o desejo das gestantes de serem atendidas por profissionais atenciosos, competentes, pacientes, envolvidos, dispostos a ajudá-las, ouvi-las e a dialogar com elas, em um ambiente privativo: [...] eu não gostaria de ficar no quarto junto assim com outras pacientes porque é meio chato. Já é constrangido ficar esperando a hora do parto com mais duas, três, quatro e até mais dentro de um quarto, [...] e mais o parto ainda! Eu não gostaria não! (L, 36 anos, $4^{\text {a }}$ gestação).

As gestantes têm conhecimento da realidade das maternidades, as quais mantêm várias parturientes num mesmo ambiente, onde elas não têm privacidade para expressar a dor ou quaisquer outros sentimentos, sejam eles positivos ou negativos, pois se sentem constrangidas nessa experiência tão pessoal. Da mesma forma, mulheres canadenses consideraram, como fator positivo, o interesse pela privacidade e pela dignidade ${ }^{10}$, e a Organização Mundial da Saúde (OMS) recomenda somente a presença de pessoas realmente necessárias, na sala de parto, como condições para o bem-estar da mulher. ${ }^{11}$

Em geral, no cotidiano das maternidades de Londrina, o respeito à privacidade das mulheres não é valorizado; profissionais se apropriam de seus corpos, de maneira insensível, ao tratá-las com impessoalidade e ao adentrar o ambiente sem pedir licença. A situação denota que não consideram a sua condição de pessoa, que deve ser respeitada e protegida em seu direito.

As gestantes não gostariam de ficar sozinhas, e destacam a companhia do marido, da mãe e da família. Justificaram este cuidado como uma forma de receber ajuda e atenção e de sentir segurança: [...] que minha mãe tivesse presente, meu marido... [...] $\left(\mathrm{K}, 30\right.$ anos, $1^{\text {a }}$ gestação); eu gostaria que tivesse sempre uma pessoa em minha companhia [...] (F, 30 anos, $1^{\text {a }}$ gestação); eu quero que o tempo todo eu tenha um acompanhamento, tanto do meu esposo como da minha família [...] (U, 21 anos, $1^{\text {a }}$ gestação).

Diversos estudos comprovaram os benefícios da presença de um acompanhante durante o parto; do envolvimento da mulher na tomada de decisão; e de sua satisfação com a experiência de parto, entre outros. ${ }^{8,10-13}$
A presença do profissional de saúde durante o trabalho de parto surgiu como uma possibilidade de redução do medo, devido à atenção que a mulher pode receber: [...] ter o médico na hora certa, [...] não ficar passando muitas dores sem ter ninguém por perto, uma enfermeira ou um médico dando atenção, [...] eu tenho medo de ficar no quarto sentindo dores, e não ter o atendimento dos profissionais (L, 36 anos, $4^{\mathrm{a}}$ gestação). As parturientes desejam alguém que possa segurar sua mão, ou mesmo oferecer uma orientação. Estas ações são traduzidas como apoio, conforto, alívio, carinho, uma mão amiga, segurança, ânimo, uma atitude de quem se importa com o outro. ${ }^{14}$

O acompanhante solicitado pelas gestantes pode ser um profissional de saúde, ou, simplesmente, alguém preparado para permanecer "por perto" e "ajudar". Essas características são compatíveis com a doula: eu acho assim, eu queria que alguém tivesse perto de mim, nem que não fosse da família, mas que fosse alouém que pudesse me ajudar também ali, de estar por perto [...] (C, 32 anos, $4^{\text {a }}$ gestação). A OMS descreve a doula como uma prestadora de serviços e uma presença amiga constante, treinada para fornecer apoio emocional, conforto físico e explicações sobre os procedimentos da assistência ao parto. ${ }^{11}$

Algumas gestantes atendidas pelo sistema de saúde suplementar elaboraram o plano de parto: [...] então, existe um documento que não tem força judicial nenhuma, é um documento só de expressão de vontade, que é o plano de parto, [...]. E eu tô preenchendo, [...] eu gostaria que a minha vontade fosse considerada e na hora de tomar uma decisão, de tomada de decisão pelos profissionais, e que se fosse possível, que ela fosse respeitada ( $\mathrm{K}, 30$ anos, $1^{\mathrm{a}}$ gestação). O plano traçado pela mulher e ou casal é, primeiramente, um instrumento educativo, que informa sobre todas as alternativas disponíveis na assistência ao parto, com ou sem intercorrências. Com uma relativa simetria entre a usuária e o provedor de cuidados, poderão concretizar-se mudanças nas práticas dos serviços, o que possibilitará à mulher a chamada escolha informada sobre "onde, como e por quem" o parto será realizado; assim, ela fica consciente de seus direitos e se comunica melhor com os profissionais de saúde. . $^{15,16}$

As preferências pessoais das gestantes que planejaram o parto com os seus obstetras foram cuidadosamente discutidas, apesar de não serem totalmente adequadas às políticas hospitalares restritivas. Pelo contrário, as metas do sistema hospitalar divergem das de um plano de parto in- 
dividualizado ou, simplesmente, das necessidades mais simples da mulher. ${ }^{17} \mathrm{O}$ objetivo deste plano de parto individualizado é ser um instrumento de facilitação da comunicação entre a mulher e o seu cuidador durante o parto, o que implica em um diálogo durante toda a gestação e no momento do evento, de modo a favorecer a confiança, o respeito e a autonomia de todos os envolvidos. Porém, torna-se difícil ter um diálogo quando mulheres e cuidadores têm visões de mundo opostas e os profissionais pensam que não têm tempo para conversar. ${ }^{18}$

Por meio de uma comunicação efetiva, da reciprocidade de intenções e da afinidade dos "motivos-para", as gestantes que construíram o plano de parto puderam estabelecer uma interação social com os seus médicos. No mundo intersubjetivo destes sujeitos, foi possível viver a relação face a face; assim, houve crescimento mútuo, diálogo e transformações internas, considerando-se que um conseguiu ver o outro como pessoa e viver a relação "nós". Nessa relação de reciprocidade, um reconheceu a necessidade do outro e as preferências das gestantes puderam ser ouvidas e atendidas.

\section{Tomada de decisão}

O envolvimento das mulheres na tomada de decisão está entre os dez princípios do cuidado perinatal abordados pela OMS no manejo do parto normal. ${ }^{19}$ Para a mulher, tomar decisões informadas significa pensar sobre a informação disponível mais completa a respeito dos cuidados que irá receber no parto e, então, decidir o que é melhor para ela e seu filho.

O empoderamento da mulher, ou seja, a sua capacidade para discutir e decidir sobre os cuidados a serem realizados no parto e nascimento, apareceu, de modo frágil, nos depoimentos. No entanto, algumas gestantes buscaram, espontaneamente, informações à respeito do parto, e decidiram, junto com o obstetra, como gostariam de parir, o que resultou na elaboração do plano de parto previamente discutido. Destaca-se a decisão segura das mulheres pela experiência do parto natural, com liberdade de dar à luz sem analgesia e sem indução com ocitocina, e pela escolha da posição de parto: [...] o parto em si, eu quero que seja na água, eu não quero que me seja oferecido nenhum tipo de analgesia e anestesia, porque eu quero pedir, se eu precisar ( $\mathrm{K}, 30$ anos, $1^{\mathrm{a}}$ gestação); a decisão que eu já tenho desde o início é do parto normal [...] que venha sozinho, que não tenha que ter indução nenhuma (A, 19 anos, $1^{\text {a }}$ gestação). Esta opção pelo modo natural de parir evidenciou que a experiência da dor que estas mulheres, possivelmente, teriam, não foi um fator de preocupação para que elas solicitassem intervenções médicas. Pelo contrário, sentiam-se capazes de parir naturalmente e ficariam muito satisfeitas se fossem respeitadas em suas decisões, sem a realização de qualquer procedimento desnecessário. Elas recorreram, também, às suas bagagens de conhecimentos disponíveis e às tipificações que foram sendo construídas, em relações face a face, nas quais os indivíduos atribuem motivos típicos aos seus semelhantes. As experiências diretas do mundo social, que permitem as relações uns com os outros, foram o ponto de partida para que estas gestantes pudessem decidir a forma de parir. Com base no depoimento de outras mulheres sobre suas experiências de gestação e parto e em informações de um obstetra disponível a ouvilas, as mulheres conseguiram projetar o próprio parto, conscientes de suas escolhas.

Entre as decisões sobre a experiência de parturição, também esteve o contato imediato com o filho, logo após o nascimento, principalmente o tipo pele a pele: [...] eu quero que o bebê fique no meu colo, ali, aconchegado por um tempo, [...] que nada comprometa o nosso primeiro contato com o nosso bebê, nada desnecessário ( $\mathrm{K}, 30$ anos, $1^{\mathrm{a}}$ gestação).

Ficou evidente o desejo das mulheres pelo contato precoce com o filho para atender à expectativa, simples e natural, de viver o momento tão especial e desejado do primeiro encontro com ele: sentir a pele, conhecer o rosto, olhar nos olhos, ser reconhecida por ele, permanecer ligada pelo cordão umbilical por mais um tempo, antes da separação, ter um tempo para se adaptarem, como família, com a inclusão do pai neste momento. Este desejo surgiu como uma característica típica deste grupo social - gestantes em último trimestre de gestação - e a proximidade do parto pode estar relacionada a este resultado.

Algumas expressões demonstraram uma atitude passiva ou uma reação de constrangimento das mulheres diante da postura profissional do médico. Encontravam-se no terceiro trimestre de gestação e ainda não tinham conversado com seus obstetras sobre o parto, sendo que, alguns deles, haviam prorrogado o assunto para o final do período gestacional ou planejaram conversar somente no dia da internação: eu pensei em conversar com o meu médico e dizer que eu gostaria de conversar mais sobre o parto, tudo. Mas assim, decisões, acho que eu ainda não pensei a respeito disso (F, 30 anos, $1^{\mathrm{a}}$ gestação). 
A falta de informação sobre como seriam as experiências de parto parece estar relacionada à atitude de omissão e ou de desinteresse do médico em compartilhar sua opinião e, muitas vezes, a sua decisão, com as mulheres; essas informações são muito valorizadas por elas, especialmente, no final da gravidez. Neste período, a mulher fica frágil e preocupada com a saúde do feto, tornase vulnerável à decisão do médico e, por não ser consultada sobre o assunto, acaba por conceber a ideia de que o parto deve ser conduzido, exclusivamente, por ele.

Neste sentido, um depoimento desvela como algumas informações podem ser tendenciosas e confundir a gestante, que está desinformada e se sente insegura diante da expectativa do parto. A mulher teve dúvida sobre a conduta médica, tentou confiar no profissional e, por fim, não conseguiu tomar nenhuma decisão, nem foi convidada a participar do planejamento do seu parto: [...] eu falei pro médico que eu queria parto normal [...] ele falou: olha, às vezes, é muito melhor você fazer a cesárea do que você fazer parto normal, [...] por exemplo, pode sofrer muito e dar problema no períneo, [...]. Pelo jeito que eu percebi, [...] parece que ele é favorável à cesárea [...] agora, não sei se é melhor a cesárea [...] em nenhum momento ele falou de parto normal! [...] Aí, eu não sei [...] entregar na mão de Deus. Deus sabe o que é melhor $\left(\mathrm{R}, 37\right.$ anos, $1^{\mathrm{a}}$ gestação). Este depoimento revela que não houve reciprocidade no atendimento pré-natal, pois o médico não oportunizou uma conversa sobre o parto normal; o profissional desconsidera a necessidade de informar a gestante, a relação face a face não se estabelece, a interação não se efetiva e a mulher não se sente suficientemente informada e esclarecida. A relação face a face pressupõe a simultaneidade de cada uma das correntes distintas de consciência, ou seja, a possibilidade de cada participante se tornar, nessa interação, intencionalmente consciente da realidade do outro. ${ }^{7}$

Neste estudo, independente do sistema de saúde utilizado, as mulheres menos informadas foram as excluídas da tomada de decisão sobre a definição do tipo de parto, resultado diferente do observado em um estudo realizado em São Paulo-SP, que considerou as diferenças sociais como comprometedoras do poder de decisão das mulheres em relação ao processo de parto. ${ }^{20}$

As gestantes pesquisadas demonstraram que se sentiam motivadas pelos planos que haviam sonhado em relação à experiência de parto que em breve vivenciariam. A expectativa do parto normal fez parte da situação biográfica delas, determinada quando elaboraram o projeto, mas também proveniente da sedimentação de todas as experiências anteriores, não como anônimas, mas enquanto únicas e dadas subjetivamente. Algumas delas demonstraram uma atitude mais ativa, ao verbalizarem que tiveram dificuldade de encontrar um obstetra que aceitasse a opção pelo parto normal e, assim, viram-se diante da possibilidade de serem submetidas a uma cesárea desnecessária; entretanto, posteriormente, conseguiram encontrar outro médico para fazer o pré-natal e o parto: [...] comecei com um médico e quando eu percebi que a linha dele não era parto normal [...] eu resolvi trocar de médico (AK, 28 anos, $1^{\text {a }}$ gestação); [...] eu troquei umas quatro vezes de médico [...] uns são radicalmente contra, outros são a favor falsamente [...] (K, 30 anos, $1^{a}$ gestação).

No mundo das relações sociais, duas teses se complementam: reciprocidade de motivos e de intenções. Há reciprocidade de motivos quando um ator social, ao se dirigir a outro, espera provocar uma ação da parte deste, de modo a estabelecer uma compreensão mútua. ${ }^{7}$ Assim, o "motivopara" de uma pessoa se torna o "motivo-porque" dos atos da outra. Já a reciprocidade de intenções se estabelece quando as pessoas envolvidas numa dada situação raciocinam como se estivessem no lugar da outra e vivenciam a situação comum da perspectiva da outra e vice-versa. ${ }^{21} \mathrm{Na}$ relação social entre médicos e gestantes, não se percebeu reciprocidade de motivos e de intenções, em vários casos. Após terem realizado várias ações para alcançar o tipo de parto de sua escolha, as gestantes optaram por trocar de médico, para que seus projetos pudessem ser concretizados.

O conhecimento sobre os modelos de assistência ao parto pode ser favorecido por condições de classe social, uma vez que a escolha informada foi possível para um grupo de mulheres que possuía curso superior e um nível socioeconômico que permitiu o acesso à internet, TV por assinatura, vídeos, livros e artigos que abordavam o tema. ${ }^{22}$ Este achado reafirma os relatos das mulheres deste estudo, pois as mais informadas também foram aquelas com melhores condições socioeconômicas e culturais. Estas, inclusive, puderam escolher outro médico para acompanhar o parto em função da existência de um plano de saúde.

Chamou a atenção o fato de algumas gestantes chegarem ao terceiro trimestre com uma atitude passiva diante da falta de atenção dos profissionais de saúde aos seus projetos, no que diz respeito ao 
parto. Este fato revela a falta de consciência dessas gestantes quanto aos seus direitos de compartilhar sonhos e anseios e de receber um cuidado individualizado, de acordo com as suas preferências, do profissional que as acompanha. Assim, apesar de almejar ser bem assistida e participar das decisões sobre o parto e de verbalizar estas necessidades e desejos, a mulher, muitas vezes não realiza ações para concretizar tais anseios.

Na tomada de decisão sobre o parto, relacionada aos "motivos-para", as gestantes puderam falar de seus planos para o futuro em relação a essa experiência, com base na possibilidade de tomar decisões. A intenção de alcançar um fim preconcebido, ou seja, o estado de coisas previamente imaginado e produzido pela ação futura, constitui o "motivo-para" desta ação. O mundo vida não pode ser experienciado de modo solitário, pois as pessoas atuam em um cenário compartilhado com as outras, assim, interferem no espaço, na linguagem, no aprendizado e nas relações mútuas, de modo intersubjetivo. $\mathrm{O}$ mundo do senso comum, o mundo da vida, o dia a dia, onde todos estão inseridos, é o mundo social, na concepção de relação social, de relacionamento entre dois ou mais sujeitos. ${ }^{9}$

\section{CONCLUSÕES}

De modo geral, independente do sistema de saúde utilizado, as gestantes não encontram condições favoráveis para que suas necessidades de cuidado e de participação nas decisões sobre o parto sejam ouvidas e viabilizadas. Não há, na grande maioria dos casos, relação face a face com os profissionais responsáveis pelo cuidado pré-natal, o que inviabiliza o direito à escolha informada em relação ao parto. Esta é a realidade do mundovida das gestantes deste estudo. Elas experimentam e interpretam este mundo intersubjetivo que é o cenário e, também, o objeto de todas as ações e interações vividas com seus semelhantes, para que seus propósitos sejam alcançados. Encontram resistências que nem sempre são superadas, pelo contrário, rendem-se a elas quando suas possibilidades de ação não podem modificá-las. Essas resistências, que compreendem: a insensibilidade dos profissionais às suas necessidades; as condições do sistema de saúde, público ou privado; a falta de informações; a insegurança e o medo revelados; e os sonhos não atingidos, acabam por produzir frustrações nessas mulheres.

As gestantes têm um projeto, que é o parto normal, e, para tanto, algumas delas agem com a intenção de concretizá-lo. A ação configura-se na busca por um médico que respeite a fisiologia do parto e não realize uma cesariana desnecessária. Não é uma ação latente, uma fantasia, elas realmente transformam a realidade que está ao seu redor.

$O$ reconhecimento à individualidade da mulher e a percepção de suas necessidades fazem parte da ação humanizada e geram relações menos desiguais e menos autoritárias. Com base em prática ética e fundamentada em evidências, o parto deve ser considerado como fenômeno fisiológico no qual a mulher se insere como condutora do processo.

Considerando-se que os fenômenos não se revelam totalmente em apenas uma abordagem, pois são construções sociais e, assim, apresentam inúmeras perspectivas e são muito abrangentes, novos estudos podem desvelar outras facetas do fenômeno aqui analisado, ou seja, podem buscar outras informações junto a gestantes ou a profissionais da área da saúde que cuidam dessa clientela.

\section{REFERÊNCIAS}

1. Armellini CJ, Luz AMH. Acolhimento: a percepção das mulheres na trajetória da parturição. Rev Gaúcha Enferm. 2003 Dez; 24(3):305-15.

2. Fustinoni SM, Merighi MAB. As necessidades de cuidado da parturiente: uma perspectiva compreensiva da ação social. In: Merighi MAB, Praça NS, organizadoras. Abordagens teóricometodológicas qualitativas: vivência da mulher no período reprodutivo. Rio de Janeiro: Guanabara Koogan; 2003. p.107-19.

3. Horey D, Weaver J, Russell H. Information for pregnant women about caesarean birth. Cochrane Database Syst Rev. 2004; 18(1):CD003858.

4. Blix-Lindstrom S, Christensson K, Johansson E. Women's satisfaction with decision-making related to augmentation of labour. Midwifery. 2004 Mar; 20(1):104-12.

5. Diniz CSG. Humanização da Assistência no Brasil: os muitos sentidos de um movimento. Ciênc Saúde Coletiva. 2005 Jul-Set; 10(3):627-37.

6. Carvalho GM, Merighi MAB, Jesus MCP. The experience of repeated fatherhood during adolescence. Midwifery. 2008 Dec 10. [ahead of print]

7. Schütz A, Luckmann T. Las estructuras del mundo de la vida. Buenos Aires(AG): Amorrortu; 2003.

8. Domingues RMSM, Santos EM, Leal MC. Aspectos da satisfação das mulheres com a assistência ao parto: contribuição para o debate. Cad Saúde Pública. 2004; 20 Supl 1:52-62.

9. Schutz A. El problema de la realidad social. Escritos I. Buenos Aires(AG): Amorrortu; 2003. 
10. Theroux $R$. The canadian maternity experiences survey: pregnancy and birth experiences of canadian women. Nurs Womens Health. 2009 Feb; 13(1):70-3.

11. Organização Mundial de Saúde. Maternidade segura: assistência ao parto normal - um guia prático. Genebra: OMS; 2000.

12. Hodnett ED, Gates S, Hofmeyr GJ, Sakala C. Continuous support for women during childbirth. Cochrane Database Syst Rev. 2007; 18(3):CD003766.

13. Brüggemann OM, Osis MJD, Parpinelli MA. Apoio no nascimento: percepções de profissionais e acompanhantes escolhidos pela mulher. Rev Saúde Pública [periódico na Internet]. 2007 Fev [acesso 2009 Ago. 15]; 41(1):44-52. Disponível em: http://www. scielo.br/pdf/rsp/v41n1/5409.pdf

14. Caron OAF, Silva IA. Parturiente e equipe obstétrica: a difícil arte da comunicação. Rev Latino-am Enferm. 2002 Jul-Ago; 10(4):485-92.

15. Diniz CSG. Entre a técnica e os direitos humanos: possibilidades e limites da humanização da assistência ao parto [tese]. São Paulo (SP): Faculdade de Medicina, Universidade de São Paulo; 2001.

16. Yam EA, Grossman AA, Goldman LA, Garcia SG. Introducing birth plans in México: an exploratory study in a hospital serving low-income mexicans. Birth. 2007 Mar; 34(1):42-8.
17. Lothian J. Birth plans: the good, the bad, and the future. J Obstetr Gynecol Neonatal Nurs [serial on the Internet]. 2006 Mar-Apr [acesso $2009 \mathrm{Jul}$ 24]; 35(2):295-303. Disponível em: http://www3. interscience.wiley.com/journal/118588344/issue

18. Perry C, Quinn L, Lindermann NJ. Birth plans and professional autonomy. Hastings Center Report [serial on the Internet]. 2002 Mar-Apr [acesso 2009 Ago. 19]; 32:12-3. Disponível em: http:/ / findarticles. com/p/articles/mi_go2103/is_2_32/ai_n6803857/

19. Chalmers B, Mangiaterra V, Porter R. WHO principles of perinatal care: the essential antenatal, perinatal, and postpartum care course. Birth [serial on the Internet]. 2001 Sep [acesso 2009 Jul 22]; 28:202-7. Disponível em: http:/ / www3. interscience.wiley.com/journal/119023288/issue

20. Merighi MAB, Carvalho GM, Suletroni VP. O processo de parto e nascimento: visão das mulheres que possuem convênio saúde na perspectiva da fenomenologia social. Acta Paul Enferm. 2007 OutDez; 20(4):434-40.

21. Wagner HR, organizador. Fenomenologia e relações sociais: textos escolhidos de Alfred Schütz. Rio de Janeiro: Zahar; 1979.

22. Medeiros RMK, Santos IMM, Silva LR. A escolha pelo parto domiciliar: história de vida de mulheres que vivenciaram esta experiência. Esc Anna Nery Rev Enferm. 2008 Dez; 12(4):765-72. 